ARTICLE

\title{
Development Research on Integrating CNC Machine Tool with Plasma for On-line Surface Heat Treatment
}

\author{
Shao-Hsien Chen ${ }^{1 *}$ and Bo-Ting Wang ${ }^{2}$
}

1 The Graduate Institute of Precision Manufacturing, National Chin-Yi University of Technology, No.57, Sec. 2, Zhongshan Rd., Taiping Dist., Taichung 41170, Taiwan

2 Department of Mechanical Engineering, National Chin-Yi University of Technology, No.57, Sec. 2, Zhongshan Rd., Taiping Dist., Taichung 41170, Taiwan

* Corresponding author: Email e6036@ncut.edu.tw

\begin{abstract}
In this study, the plasma was integrated with a lathe, and the online heat treatment was performed to achieve mechanical strength and hardness, to reduce the machining process and handling. However, for online heat treatment cast iron FC25, it is important to study the parameters of the lathe and plasma, and the research method is used eventually to optimize the process, reduce the machining cost and machining error. The variable factors in the surface online real-time heat treatment are spindle speed, feed rate, and current, the objective function is the hardness of mechanical properties. In the screening experiment, the interaction of factors was discussed using a full factorial experiment. The Central Composite Design was combined with the Lack-of-Fit test for the optimization experiment, the $\mathrm{R}^{2}$ coefficient was used to determine whether the regression model is appropriate. The optimum parameters were derived from the contour diagram and response surface diagram. The experimental results show that the significant factors include spindle speed, feed rate, and current, the optimum parameters include spindle speed $168 \mathrm{rpm}$, feed rate $0.068 \mathrm{~mm} / \mathrm{rev}$, and current $86 \mathrm{~A}$. The experimental results of optimum parameters show that the surface hardness is increased from 306HLD to 806HLD, the surface hardening effect is enhanced by $163 \%$, so the online real-time heat treatment equipment has the best hardening effect.
\end{abstract}

Keywords: plasma hardening; response surface methodology; cast iron

\section{Introduction}

Under the large output value of the automobile industry, the demand for automobile metal plates increases gradually. The automobile metal plates are machined by stamping, bending, and stretching, so the machining or handling of the large-sized metal plate molds takes a lot of time. The metal plate molds are high-cost processed bests. To prolong the service life of molds, surface heat treatment is required during machining to implement surface hardening. The flame treatment is mostly used at present. This study will use plasma in the lathe (CNC lathe) to study parameters, aiming at online real-time surface heat treatment, to achieve mechanical properties and surface hardening. Li et al. [1] used high energy density of plasma for quench hardening of tank parts. The result showed that the part surface hardness was higher than HRC55, the deformation was $0.01 \mathrm{~mm}$, the depth of hardening was $0.02 \mathrm{~mm}$, applicable to partial hardening, the result was best, the service life of parts was prolonged. For long-term operation and maintaining the stability of the plasma machine, Zhou [2] designed a plasma control system, and the machine values were visualized. This system extracted the current and voltage variations in the experiment, it was used in multiple steel products for surface treatment, the average surface hardness was HRC52 62. Cui et al. [3] used the plasma surface treatment technique for enhancing the gear hardness, the result showed that the plasma surface treatment enhanced the gear surface hardness and wear resistance, and the gear size and tooth shape would not be deformed by the treatment process. The surface hardening value was $750 \sim 850 \mathrm{HV}, 15 \sim 20$ times of the material hardness before treatment, the hardened layer was $0.15 \sim 0.3 \mathrm{~mm}$ thick. Yang [4] performed mathematical derivation for the theoretical 
basis of plasma arc surface quenching temperature simulation and built a plasma heat source model. The analytical software ANSYS was used for analyzing the distribution of the overall temperature field of quenching, and the arc power, feed rate, plasma head nozzle hole diameter, workpiece preheating, and the parameters of different cooling methods were tested. The validation experiment was performed at last. The experimental results matched the software analysis results. 5 . Used finite element analysis to study the distribution patterns of temperature field and stress field of $40 \mathrm{Cr}$ steel product and used X-ray stress detector to test the residual stress after quenching of $40 \mathrm{Cr}$ steel product. In terms of the plasma quenching cooling method, the workpiece generates stress by its heat transfer, this stress is residual compressive stress [5]. The fatigue failure of the workpiece surface can be improved effectively according to analysis, but the workpiece is likely to a flaw. The result showed that the nozzle diameter and output current had a relatively greater influence on residual compressive stress. The used laser to treat the surface of AISI 4140 intermediate-carbon chrome-molybdenum steel, and analyzed the improved mechanical properties after treatment. The result showed that the metallographic structure was changed from materials ferrite and pearlite into plumose martensite structure, the surface hardness was increased by $238 \%$ from Hv237 to 771 , the material yield strength was $94 \mathrm{~kg} / \mathrm{mm}^{2}$, and $125 \mathrm{~kg} / \mathrm{mm}^{2}$ after laser processing, the amplitude was $33 \%$, the tensile strength was increased by $14 \%$ from $118 \mathrm{~kg} / \mathrm{mm}^{2}$ to $139 \mathrm{~kg} / \mathrm{mm}^{2}$ [6]. The used laser to treat the surface of AISI 4140 chrome-molybdenum steel, M2 tool steel, and a new type of steel KDIIS. The experimental results showed that the surface hardness of AISI 4140 was Hv750 after laser surface treatment, that of M2 tool steel was Hv1200, and that of a new type of steel KDIIS was Hv1200. In the experimental process, the temperature rose rapidly to austenitizing temperature and dropped rapidly, and the carbon atoms in the material had no time to generate cementite. The BCT crystal was obtained, and the lattice was distorted, so the hardness was quite high, and it was a martensite structure [7].

The hardened layer hardness distribution and metallographic structure variation after laser surface treatment of material carbon tool steels SK3, SK5, and SK7 and die steel SKD61. The case hardness of carbon tool steel SK3 was Hv910, the case hardness of SK5 was Hv900, the case hardness of SK7 was Hv950, and the case hardness of die steel SKD61 was Hv1100. The main hardening condition of dies steel SKD61 depended on whether the carbides were dissolved in the base austenite or not. The structure was divided into three parts after quenching, including hard zone, transition zone, and substrate zone. The distribution of carbides in the hard zone decreased obviously because the high temperature of laser surface treatment dissolved surface carbides in the base, the hard zone had the highest hardness value, the transition zone and substrate zone were tempered martensite structure and fine carbides $[8,9,10]$

The mechanical properties of medium carbon steel AISI 1045, chrome-molybdenum steel AISI 4140, and nickel-chromium-molybdenum steel AISI 4340 after laser surface treatment. The experimental results showed that the hardness of medium carbon steel AISI 1045 was increased from $316 \mathrm{HV}$ to $755 \mathrm{HV}$, the surface hardness was increased by $138 \%$. The hardness of chrome-molybdenum steel AISI 4140 was increased from Hv396 to Hv801, the surface hardness was increased by $102 \%$. The hardness of nickel-chromiummolybdenum steel AISI 4340 was increased from $441 \mathrm{HV}$ to $833 \mathrm{HV}$, the surface hardness was increased by $88 \%$. The depth of hardening of medium carbon steel AISI 1045 was $0.85-1.45 \mathrm{~mm}$, the depth of hardening of chrome-molybdenum steel AISI 4140 was 0.96$1.65 \mathrm{~mm}$, the depth of hardening of nickel-chromium-molybdenum steel AISI 4340 was 0.91-1.88mm. According to the above references, laser hardening was mostly used. This study will combine plasma hardening with response surface methodology to study parameter optimization, the hardening effect can be achieved at a lower cost, but there is no related study at present $[11,12]$. Reviewing data published in the literature reveals that the phenomenon reported in this paper has not surface hardening of the Plasma and lathe integration observed. The objectives of this study include (1) evaluating the hardening efficiency of plasma heat treatment, (2) comparing the effects of experimental parameters 
current、spindle speed and feed on hardening results, and (3) investigating the optimization and verification of plasma heat treatment parameters.

\section{Research content and method}

The heat source model and parameters shall be determined before the test because the selection of an equivalent plasma heat source mathematical model will directly influence the heat distribution of the concentrated heat source. When the concentrated heat source works [13], the temperature distribution on the metal surface close to the center of the concentrated heat source depends on the heat source type, and the temperature distribution on the metal surface far from the center of the heat source is determined by the thermophysical property of metal material. The common concentrated heat sources include point line, and surface heat sources [14,15]. It is a Gaussian heat source during plasma arc quenching [16,17]. Figure 1 shows the distribution of heat flux of Gaussian heat source, the heat flow follows Gaussian distribution, the Gaussian heat source function is expressed as Eq. (1).

$$
q(r)=q_{m} \exp \left(-k r^{2}\right)
$$

In Eq. (2.2): $q(r)$ is the heat flux density $\left(\mathrm{W} / \mathrm{m}^{2}\right)$ at radius $r ; q_{m}$ is the heat flux density $\left(\mathrm{W} / \mathrm{m}^{2}\right)$ at the center of arc column; $r$ is the distance $(\mathrm{m})$ from the center point of plasma heat source to any point of the hot zone; $k$ is the Gaussian heat source distribution curve shape coefficient $\left(\mathrm{m}^{-2}\right)$

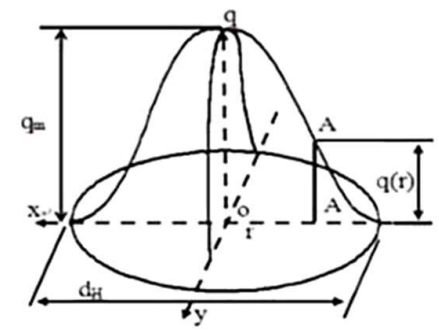

Figure 1. Gaussian heat flux distribution [16].

The effective power of plasma for heating workpiece is $[18,19,20]$

$$
q=0.24 \times \eta \times I \times V
$$

On equation (2): $\mathrm{V}$ is the plasma voltage, $\mathrm{I}$ is the plasma current value, $\eta$ is the plasma thermal efficiency

\section{Experimental equipment and planning:}

The experimental sample is FC25 gray cast iron in this study, which has the best casting property, cutting characteristic, and wear resistance. The metallographic structure of the material comprises ferrite + pearlite + flake graphite. The graphite content in the structure can achieve a self-lubricating effect. This study uses DC plasma heat source output to simulate immediate surface heat treatment after lathe finish machining. As the material metallography shall be analyzed after hardening, cutting machining is required, preventing the heat generated in the cutting process from changing the end product surface metallography. Therefore, this study uses a sample in the outside diameter of $40 \mathrm{~mm}$ and thickness of $20 \mathrm{~mm}$, the material sample is prepared before the experiment.

A single-spindle lathe as an experimental carrier and a hollow cylinder sample is used for the experiment. The lathe spindle controls the spindle speed (rpm), the plasma gun head is fastened to the cutting tool rest to control the feed rate ( $\mathrm{mm} / \mathrm{rev})$, so as to uniformly heat up the material surface. The plasma device for the experiment is of transferred arc type, numerically controlling the movement, making the plasma gun head approach the 
workpiece to form a loop, generating an electric arc for heating. In terms of heat source output, the current (A) controls the output of heat source energy magnitude. The experimental configuration is shown in figure 2 . The flow chart of the experimental analysis and model establishment of this research is shown in figure 3.
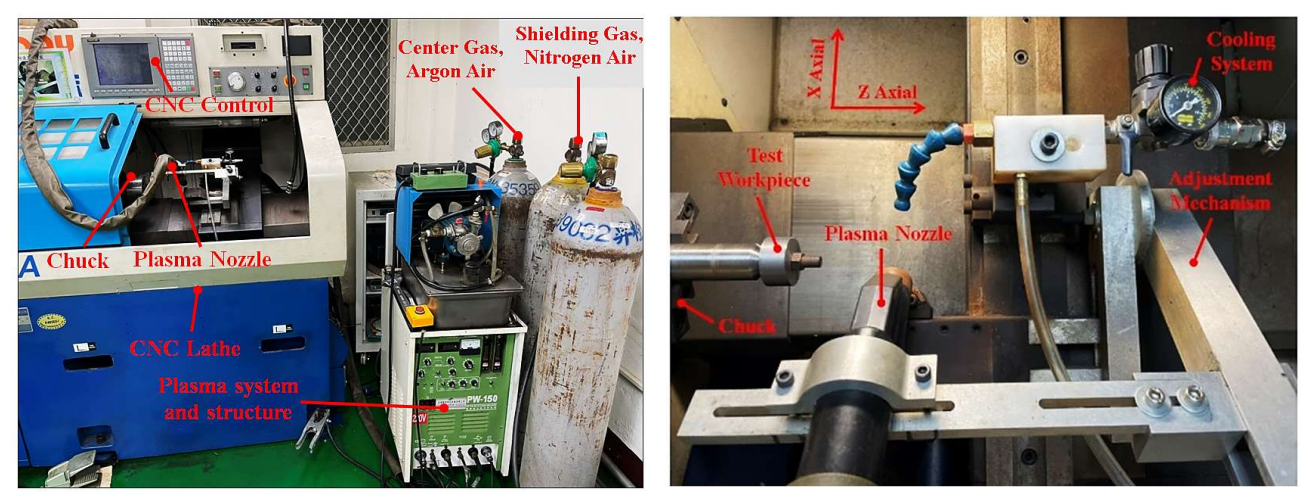

Figure 2. Lathe and plasma experiment equipment and system.

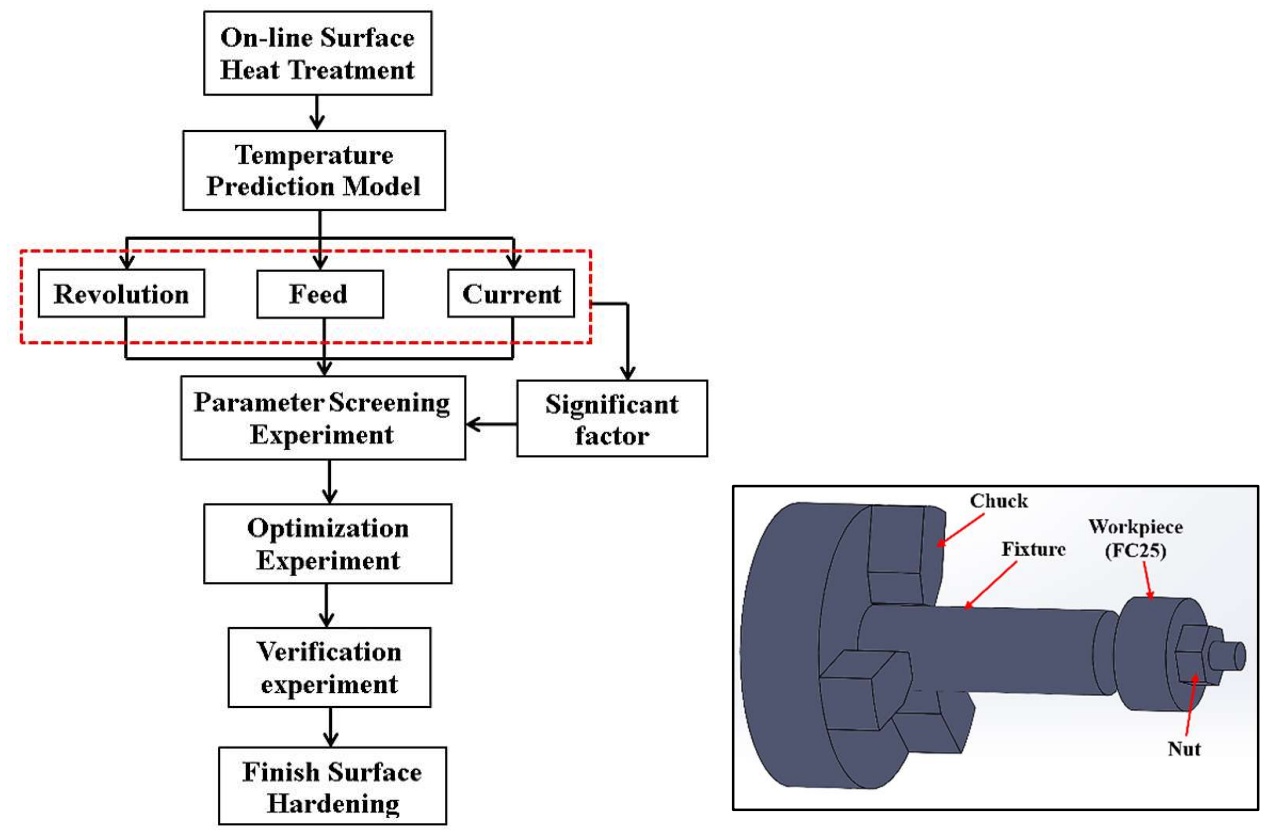

Figure 3. Experimental flowchart and process.

Figure 4. Experimental workpiece clamping

The material used in this study is cast iron FC25. The mechanical properties and components are shown in tables 1-2, the diameter, thickness, and hole of the workpiece were $40 \mathrm{~mm}$, $20 \mathrm{~mm}$, and $12 \mathrm{~mm}$, respectively. As shown in figure 4 .

Table 1 - FC25 Chemical Composition(\%)

\begin{tabular}{|c|c|c|c|c|c|c|}
\hline & $\mathrm{C}$ & $\mathrm{P}$ & $\mathrm{Si}$ & $\mathrm{Mn}$ & $\mathrm{S}$ & $\mathrm{Ti}$ \\
\hline FC25 & $3 \sim 3.3$ & $\leq 0.12$ & $1.65 \sim 2.05$ & $0.7 \sim 1.1$ & $\leq 0.12$ & $\leq 0.05$ \\
\hline
\end{tabular}

Table 2、FC25 Mechanical Properties

\begin{tabular}{|c|c|c|c|c|}
\hline & Tensile strength & Extension & Reduction of area & Hardness \\
\hline FC25 & $830 \mathrm{~N} / \mathrm{mm}^{2}$ & $\geq 20 \%$ & $\geq 45 \%$ & 306 HLD \\
\hline
\end{tabular}

\section{Results and Discussion}

4-1. Relationship between temperature and material 


\section{4-1-1. Temperature prediction model building}

This study mainly uses plasma for sudden heating of the material to generate cementite and steatite deposition, to harden the surface. Therefore, the temperature prediction model shall be built before research to confirm the current, the full factorial experiment is used in temperature prediction modeling experiment, the parameter setting experiment conditions: the outside diameter of FC25 gray cast iron is $40 \mathrm{~mm}$, the heating distance is $50 \mathrm{~mm}$, the estimated temperature rise is $100^{\circ} \mathrm{C} 300^{\circ} \mathrm{C}$, the established parameters are shown in table 3 , parameter setting refers to equation 2 , the voltage, current, and plasma thermal efficiency of the parameter were $\mathrm{V}=220 \mathrm{~V}, \mathrm{I}=40 \mathrm{~A} \sim 60 \mathrm{~A}$, and $\eta=0.23$, respectively.

Table 3. Experimental factors and levels.

\begin{tabular}{cccc}
\hline & Level I & Level II & Level III \\
\hline (A) Spindle Speed rpm & 175 & 200 & 225 \\
\hline (B) Feed rate mm/rev & 0.3 & 0.36 & 0.42 \\
\hline (B) Current A & 40 & 50 & 60 \\
\hline
\end{tabular}

The experimental parameters are designed by using RSM. The experimental results are discussed below. When the feed rate is fixed at $0.42 \mathrm{~mm} / \mathrm{rev}$, the Spindle speed is 175 225rpm and the current is 50 60A, the temperature rises as the current increases, the current is proportional to the thermal power according to Eq. 7, the maximum temperature difference is $25 \%$. In terms of spindle speed, the higher the spindle speed is, the shorter is the single-point heating time, so the temperature effect is inversely proportional to the spindle speed, the maximum temperature difference is $18 \%$. When the current is fixed at $40 \mathrm{~A}$, the spindle speed is $175 \sim 200 \mathrm{rpm}$ and the feed rate is $0.3 \sim 0.42 \mathrm{~mm} / \mathrm{rev}$, the temperature drops as the spindle speed increases because the single-point heating time is shorter, the temperature is lower, the maximum temperature difference is $10 \%$, as shown in figure 5. The lower the feed rate is, the higher is the temperature, the maximum temperature difference is $22.5 \%$. When the spindle speed is fixed at $225 \mathrm{rpm}$, the current is $40 \sim 60 \mathrm{~A}$, and the feed rate is $0.3 \sim 0.36 \mathrm{~mm} / \mathrm{rev}$, the higher the current is, the higher is the temperature. The current is proportional to the thermal power according to equation 7 , the maximum temperature difference is $60.4 \%$.

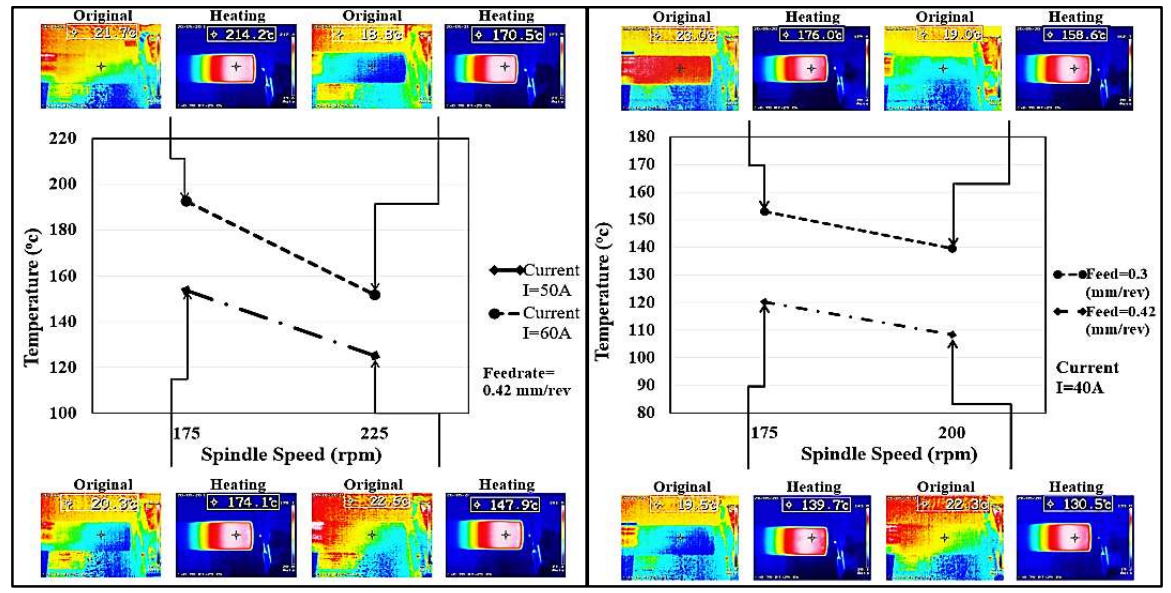

Figure 5. Relationship of different spindle speed and temperature.

The temperature prediction model is built by using temperature measurement after the test. The Partial Least Squares Method and Regression (PLSMR) and Least Square Method and Regression (LSMR) are compared. The parameters are designed by using RSM. The P-value $<0.05$ and $\mathrm{R}^{2}$ value $>0.9$ in analysis. The result of PLSMR is shown in Figure 6. It is observed that the current value is a significant factor, the order of 
contributions is current $>$ feed $>$ spindle speed, the regression prediction model is expressed as equation 4:

$$
\text { Temp }=231.5-0.621 \mathrm{~N}-333.1 \mathrm{~F}+3.454 \mathrm{I}
$$
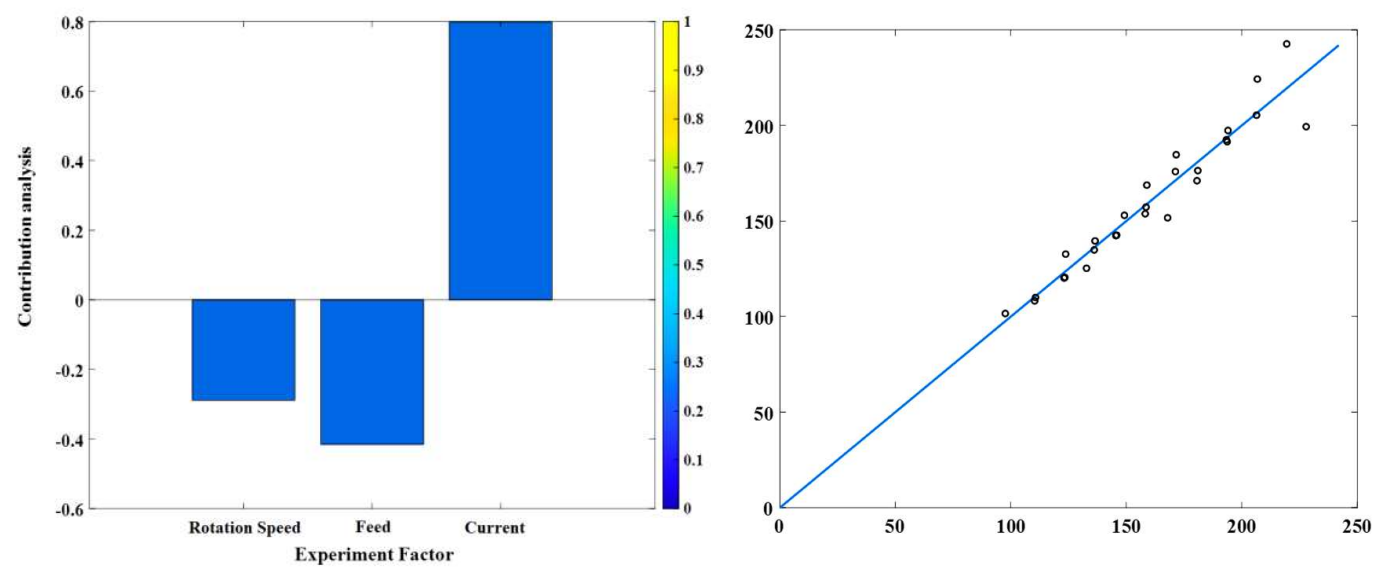

Figure 6. Partial Least Squares Method and Regression Analysis chart.

When the LSMR is used, the experimental significance level $\alpha=0.05$, and F value $=50$, $\mathrm{F}>\mathrm{F}(0.05,4,2)$ so the null hypothesis is rejected. The test coefficient $\mathrm{R}^{2}=0.9709$ means $97.09 \%$ of the total variance in the model can be explained by the independent variable, the regression model has high fitness, as shown in figure 7 . It is observed that the current value is a significant factor, the order of contributions is current $>$ feed $>$ spindle speed, the regression prediction model is expressed as Eq. 8:

$$
\mathrm{F}=\frac{422.5}{191}=221<F_{(0.05,4,2)}=19.2468
$$

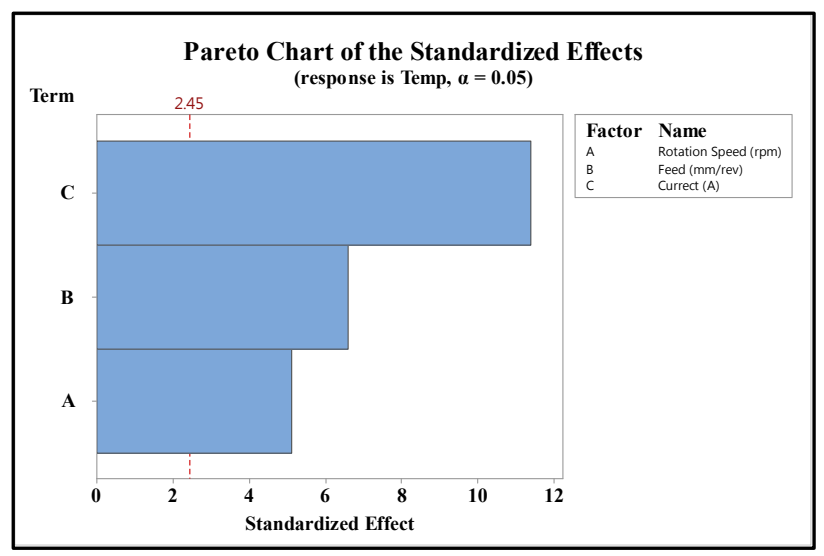

Figure 7. Least Square Method and Regression Analysis chart.

\section{4-1-2. Temperature model verification}

Five groups of arbitrary parameters will be used for temperature validation after modeling. The temperature parameters are shown in table 4 . The predicted values and experimental values are analyzed. The model verification uses MAPE (Mean Absolute Percentage Error) as a measurement indicator. The MAPE of the PLSMR model is 0.5935\%, and the MAPE of the PLSMR model is $1.335 \%$, so the PLSMR has higher accuracy, as shown in table 5 . However, both of the estimation methods are in the permissible range, the results are shown in Table 6.

Table 4. Validation experiment parameter list. 


\begin{tabular}{cccc}
\hline $\begin{array}{c}\text { Experimental pa- } \\
\text { rameter }\end{array}$ & Spindle speed rpm & Feed rate $\mathbf{~ m m / r e v ~}$ & Current \\
\hline Group 1 & 213 & 0.33 & A \\
\hline Group 2 & 213 & 0.39 & 45 \\
\hline Group 3 & 188 & 0.33 & 55 \\
\hline Group 4 & 188 & 0.39 & 55 \\
\hline & 188 & 0.39 & 45 \\
\hline
\end{tabular}

Table 5. Prediction model analysis and comparison.

\begin{tabular}{|c|c|c|c|c|c|}
\hline & Actual & $\begin{array}{c}\text { Forecasted } \\
(\text { LSMR) }\end{array}$ & $\begin{array}{c}\text { Absolute } \\
\text { Precent Error } \\
\end{array}$ & $\begin{array}{c}\text { Forecasted } \\
\text { (PLSMR) }\end{array}$ & $\begin{array}{c}\text { Absolute Precent } \\
\text { Error }\end{array}$ \\
\hline 1 & 143.8 & 146.13 & 1.62 & 144.73 & 0.65 \\
\hline 2 & 124.7 & 126.15 & 1.16 & 124.75 & 0.038 \\
\hline 3 & 195.7 & 196.20 & 0.25 & 194.80 & 0.46 \\
\hline 4 & 173.5 & 176.21 & 1.56 & 174.81 & 0.76 \\
\hline 5 & 138.8 & 141.67 & 2.07 & 140.27 & 1.06 \\
\hline \multicolumn{3}{|c|}{ MAPE } & 1.34 & & 0.59 \\
\hline
\end{tabular}

Table 6. Validation experiment measurement results.

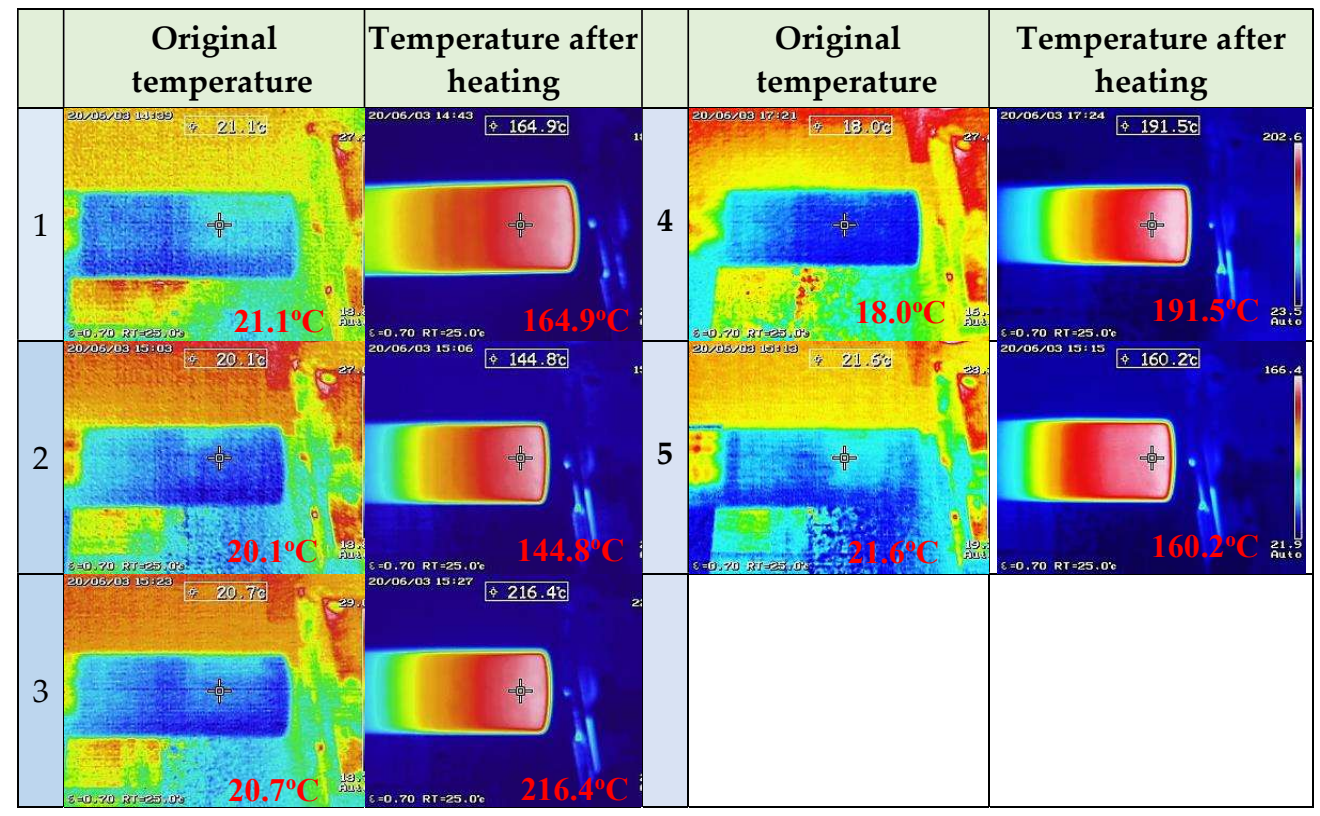

\section{4-2. Influence of different parameters on material properties}

The influence of different spindle speed, feed rates, and current values on material properties is analyzed, the spindle speed is $200 \sim 300 \mathrm{rpm}$, the feed rate is $0.1 \sim 0.2 \mathrm{~mm} / \mathrm{rev}$, and the current value is 60 80A. Different parameters correspond to different workpiece single-point action thermal effects, so the material properties are analyzed and discussed, aiming at the material hardness and metallographic structure changes. The relationships between different parameters and mechanical properties are described below.

4-2-1 the influence of spindle speed and feed on material hardness. 
The influence of different spindle speed and feed rates on the hardness of mechanical properties is mainly the influence of operative temperature at a material single point, when the plasma power is fixed at $I=80 \mathrm{~A}$, as shown in figure 8 , the hardness value is relatively higher when the spindle speed is lower because the workpiece spindle speed directly influences the heating time. When the feed rate is $0.1 \mathrm{~mm} / \mathrm{rev}$, the workpiece spindle speed is adjusted from 300rpm to 200rpm, the hardness value is increased by $35.4 \%$. The influence of feed rate on hardness is observed in this experiment. The lower the feed rate is, the higher is the hardness value, the first cause is the single-point heat source action time. When the workpiece spindle speed is 200rpm, the feed rate is adjusted from $0.2 \mathrm{~mm} / \mathrm{rev}$ to $0.1 \mathrm{~mm} / \mathrm{rev}$, the hardness value is increased by $69.3 \%$.
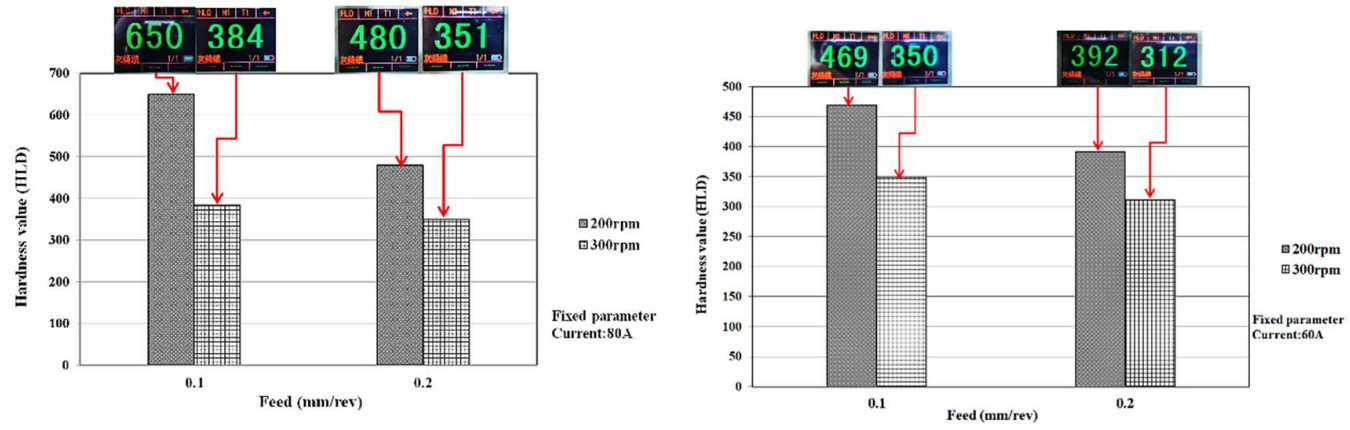

Figure 8. Relationship of different spindle speed to a hardness value.

When the plasma current is reduced to $I=60 \mathrm{~A}$, the spindle speed is $N=200 \sim 300 \mathrm{rpm}$, and the feed rate is $\mathrm{F}=0.1 \sim 0.2 \mathrm{~mm} / \mathrm{rev}$. The fundamental purpose is to heat the workpiece uniformly to achieve a hardening effect, when the spindle speed is adjusted from 300rpm to $200 \mathrm{rpm}$, the hardness value is increased by $19.6 \%$. When the workpiece spindle speed is $200 \mathrm{rpm}$, the feed rate is adjusted from $0.2 \mathrm{~mm} / \mathrm{rev}$ to $0.1 \mathrm{~mm} / \mathrm{rev}$, the hardness value is increased by $34 \%$. According to the aforesaid data, the longer the unit residence time is, the higher is the relative hardness. Under variable plasma current, the higher the current is, the more obvious is the relative hardness.

\section{4-2-2. Relationship of different current values to a hardness value}

When the feed rate is fixed, the effects of different spindle speed and plasma current values on material hardening and variation are observed. When the constant spindle speed is $\mathrm{N}=200 \mathrm{rpm}$, the current value is increased by $25 \%$ from $\mathrm{I}=60 \mathrm{~A}$ to $\mathrm{I}=80 \mathrm{~A}$, the hardening effect is increased by $27.8 \%$. When the constant spindle speed is $\mathrm{N}=300 \mathrm{rpm}$, the hardening effect is increased by $18.3 \%$. When the current value is $\mathrm{I}=80 \mathrm{~A}$, the spindle speed is increased by $33 \%$, the hardening effect is reduced by $35.4 \%$. Therefore, the higher the spindle speed is, the worse is the hardening effect, as shown in figure 9. When the spindle speed is fixed, the effects of different feed rates and plasma current values on material hardening and variation are observed. When the feed rate $F=0.1 \mathrm{~mm} / \mathrm{rev}$, the current value is increased by $25 \%$, the hardening effect is $27 \%$, and then the feed rate is increased to $\mathrm{F}=0.2 \mathrm{~mm} / \mathrm{rev}$, the hardening effect is $8.9 \%$. Therefore, the higher the feed rate is, the worse is the hardening effect. When the current value is $\mathrm{I}=80 \mathrm{~A}$, the feed rate is increased by $50 \%$, the hardening effect is reduced by $69.3 \%$ because under different parameters and temperatures, the experimental material produces different precipitates, the final hardness value is influenced, as shown in figure 9.
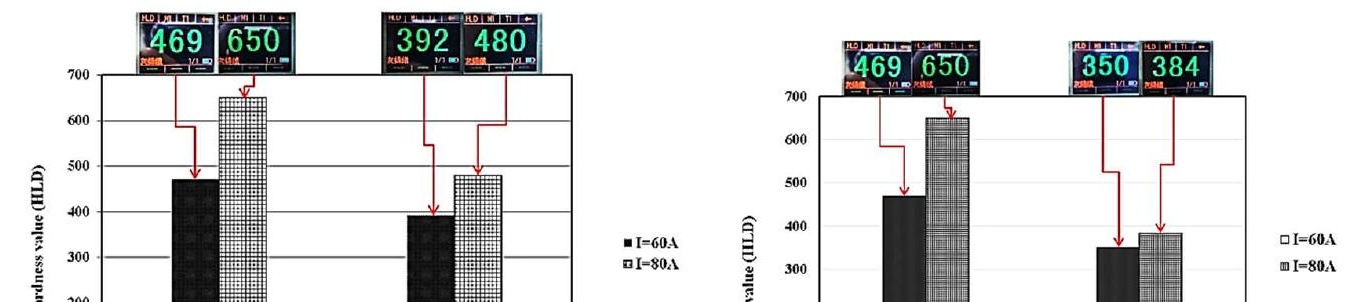
Figure 9. Relationship of different current values to a hardness value.

\section{4-2-3. Description of experimental metallographic structure}

In the online heat treatment process, the mechanical parameters influence the temperature, leading to the hardening effect, the influence on the hardening effect is closely bound up with the material structure, so the internal change is observed by using metallographic structure. The silicon content of $1.0 \sim 2.0 \%$ in the material presents the pearlite structure, the silicon can change the free carbon in the casting process into graphite crystal, the cementite generation is reduced. When the graphite content in the structure increases, the texture is relatively soft and easy to cut. The amount of silicon content results in different crystals of graphite. During molding, the iron element and carbon element perform chemical action due to the high temperature inside cast iron, so that the cementite is generated. The cementite has a hard and brittle texture, increasing the difficulty in subsequent material processing. To prevent this problem, an amount of silicon is added to the casting process, the carbon element is changed into graphite, to reduce the cementite generation. The ferrite is separated from the cementite during cooling, so a lot of ferrites adhere to the graphite crystals.

When the spindle speed $\mathrm{N}=300 \mathrm{rpm}$, feed rate $\mathrm{F}=0.1 \mathrm{~mm} / \mathrm{rev}$, and current value $\mathrm{I}=80 \mathrm{~A}$, the measured hardness is 479 HLD, higher than the material surface hardness by $57 \%$. Figure 10 shows that most of the ferrite structure is changed into pearlite, so a little graphite carbide is separated nearby the graphite crystal branches.

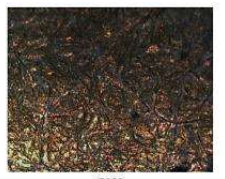

$50 \mathrm{X}$

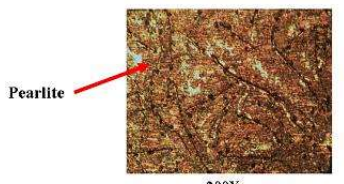

$200 \mathrm{X}$
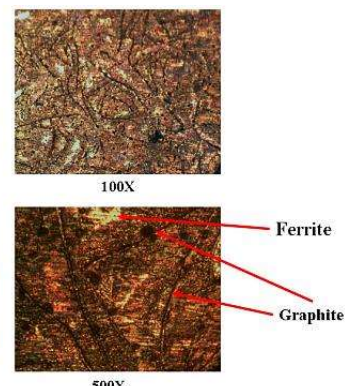

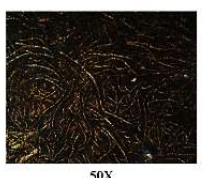

$50 \mathrm{X}$

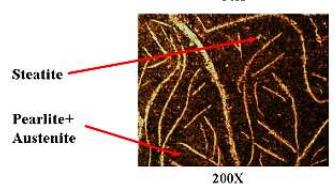

200X
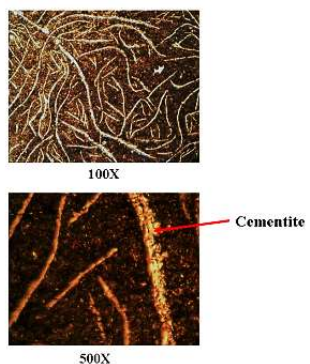

Figure 10. Phase diagram of Experiment 5 and 7

When the spindle speed $\mathrm{N}=200 \mathrm{rpm}$, feed rate $\mathrm{F}=0.1 \mathrm{~mm} / \mathrm{rev}$ and current value $\mathrm{I}=80 \mathrm{~A}$, the experimental measurement result is 613HLD, higher than the material surface hardness by $100 \%$, there is no obvious martensite feature in the structure, so the substrate is transformed from pearlite into pearlite + austenite eutectic. The experimental temperature has reached the transformation point, but the duration is too short to transform all structures, leading to this eutectic phenomenon. The heated graphite and the Fe element in the material have a chemical change to separate cementite, it is observed that the original graphite crystal branches have been replaced by cementite.

The cast iron contains phosphor element, when the phosphor element is solidified again at a high temperature, this kind of iron phosphide is called steatite. The scattered white dots in figure 10 are steatite, the hardness of steatite next to cementite, the wear resistance can be enhanced, and the heat resistance can be improved. 
To fully melt the graphite, a long heating time is required, and the temperature shall be maintained, to destroy the graphite crystal appearance. The graphite precipitates cementite out, but the shape is the same as the graphite crystal because the heating time is too short.

\subsection{Material hardening optimization experiment}

In the online hardening heat treatment process, the temperature has an obvious effect on material structure, and the material structure change can induce mechanical hardening. In Stage 2, the experimental significant factors are used for full factorial Central Composite Design. The experimental parameters adopt 3 factors and 5 levels. The experimental sequence is performed using random numbers. The design of experimental parameters is shown in table 7. After the experiment, the changed hardness of the material is used to measure and build the prediction model, the LSMR is used for analysis.

Table 7. Optimization experiment factors and levels.

\begin{tabular}{cccccc}
\hline Factor & $\mathbf{1 . 6 3 3}$ & $\mathbf{1}$ & $\mathbf{0}$ & $\mathbf{- 1}$ & $\mathbf{- 1 . 6 3 3}$ \\
\hline $\begin{array}{c}\text { Spindle speed } \\
\text { Rpm (A) }\end{array}$ & 168 & 200 & 250 & 300 & 331 \\
\hline Feed rate mm/rev (B) & 0.07 & 0.1 & 0.15 & 0.2 & 0.23 \\
\hline $\begin{array}{c}\text { Current } \\
\text { A (C) }\end{array}$ & 64 & 60 & 70 & 80 & 86 \\
\hline
\end{tabular}

First-order model Lack-of-Fit test, the Lack-of-Fit P-value of this model is $0.022<\alpha=0.05$, it is confirmed this model cannot fit data, the Lack-of-Fit F value is 9.32>

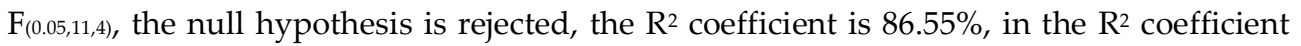
test, the value is relatively low, the analysis is performed not eliminating second-order model existence.

$$
\mathrm{F}=\frac{1490.8}{159.8}=9.32>F_{(0.05,11,4)}=5.96
$$

In the second-order model Lack-of-Fit test, the full factorial is used for analysis in Stage 1, the model Lack-of-Fit P-value is $0.284>\alpha=0.05$, there is no evidence for the failure in fitting data, the Lack-of-Fit $\mathrm{F}$ value is $1.856<\mathrm{F}(0.05,5,4)$, the null hypothesis is not rejected, the $\mathrm{R}^{2}$ coefficient is $98.32 \%$, the second-order model is more applicable than the first-order model.

$$
\mathrm{F}=\frac{296.6}{159.8}=1.856<F_{(0.05,5,4)}=6.26
$$

In Stage 2, the coefficients in the quadratic term and interaction term are insignificant, meaning the terms have a slight influence on the hardness response variable in the experimental results, so the term with low contribution is deleted, and the ANOVA is performed after an adjustment.

$$
\mathrm{F}=\frac{369.2}{159.8}=2.31<F_{(0.05,8,4)}=6.04
$$

Adjusted second-order model Lack-of-Fit test, the Lack-of-Fit P-value of this model is $0.218>\alpha=0.05$, there is no evidence indicating that the model cannot fit data, the Lackof-Fit $\mathrm{F}$ value is $2.31<\mathrm{F}_{(0.05,8,4)}$, the null hypothesis is not rejected, the $\mathrm{R}^{2}$ coefficient is $97.16 \%$, meaning $97.16 \%$ of the total variance in the model can be explained by the independent variable.

The regression equation is

$$
\mathrm{Y}=1033-3.99 \mathrm{~A}-2828 \mathrm{~B}+6.94 \mathrm{C}+0.0064 A^{2}+10596 B^{2}-26.7 B * C
$$

The regression prediction equation is built by using RSM, the validation experiment shall be performed to check whether the model meets the standard or not. The validation experiment parameters are shown in table 8 9, three groups of experimental parameters are selected at random and substituted in the equation for validation. The experimental sample is measured five times, the average value is taken, the maximum error is $2.01 \%$ according to experimental analysis and model verification. According to the aforesaid 
three groups of experimental results, the estimated values of the temperature prediction equation fall in the confidence interval, the estimation ability is best. The three groups of metallographic structure as shown in figure 11.

Table 8. Validation experiment parameter list.

\begin{tabular}{cccc}
\hline $\begin{array}{c}\text { Experimental parame- } \\
\text { ter }\end{array}$ & Spindle speed rpm & Feedrate $\mathbf{~ m m / r e v}$ & Current \\
\hline Group 1 & 200 & 0.1 & A \\
\hline Group 2 & 250 & 0.15 & 70 \\
\hline Group 3 & 300 & 0.2 & 80 \\
\hline
\end{tabular}

Table 9. Verification experiment result.

\begin{tabular}{cccc}
\hline & Actual average HLD & $\begin{array}{c}\text { Predicted } \\
\text { HLD }\end{array}$ & Error \\
\hline Group 1 & 572 & 570 & $0.35 \%$ \\
\hline Group 2 & 451 & 455 & $0.88 \%$ \\
\hline Group 3 & 406 & 398 & $2.01 \%$ \\
\hline
\end{tabular}
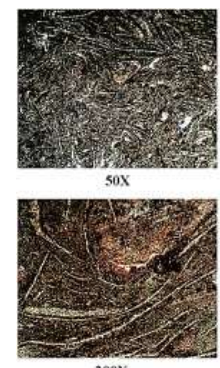

$200 \mathrm{x}$

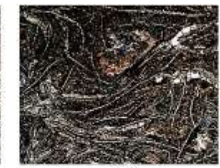

$100 \mathrm{x}$

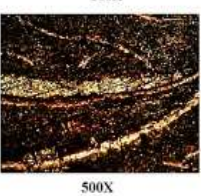

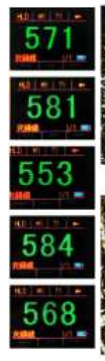

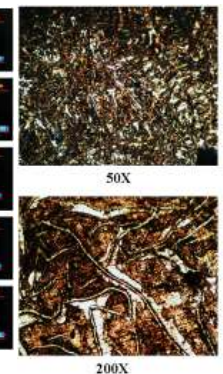

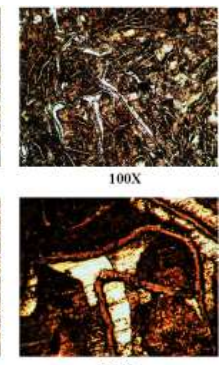

436

460

462

440

456.

Figure 11 Phase diagram and hardness of validation experiments 1 and 3

\subsection{Analysis and validation of optimum parameters}

According to analysis, the spindle speed, feed rate, and current can influence the temperature, and then the workpiece hardness and mechanical properties are influenced. According to the contour diagram of spindle speed and feed rate to surface hardness, when the current is fixed at $\mathrm{I}=70 \mathrm{~A}$, the lower the spindle speed and feed rate are, the better is the material hardening effect, the results are shown in figure 12. According to the contour diagram of feed rate and current value to surface hardness, when the spindle speed is fixed at $\mathrm{N}=250 \mathrm{rpm}$, the higher the current is and the lower the feed rate is, the better is the material hardening effect, the results are shown in figure 13. According to the contour diagram of spindle speed and current value to surface hardness, when the feed rate is fixed at $F=0.15$, the higher the current is and the lower the spindle speed is, the better is the material hardening effect, the results are shown in figure 14 . Because the shorter the distance acting on the material per unit time is, the better is the hardening effect. 


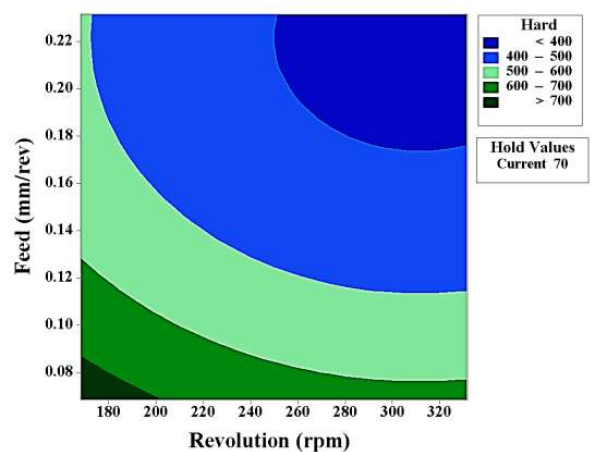

Figure 12. Contour diagram of spindle speed and feed rate to surface hardness

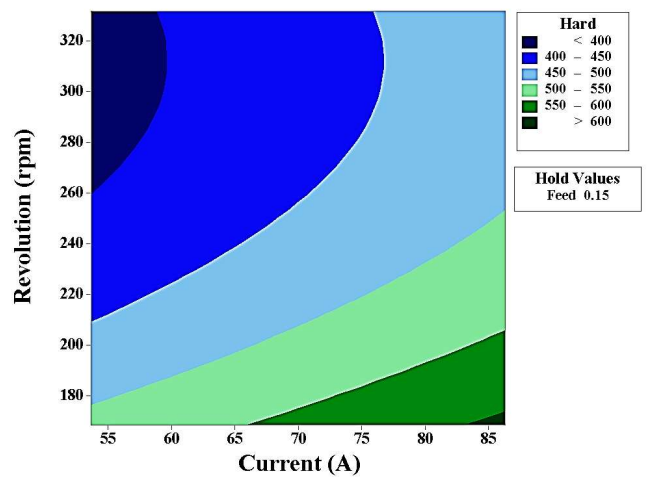

Figure 14. Contour diagram of spindle speed and current value to surface hardness.

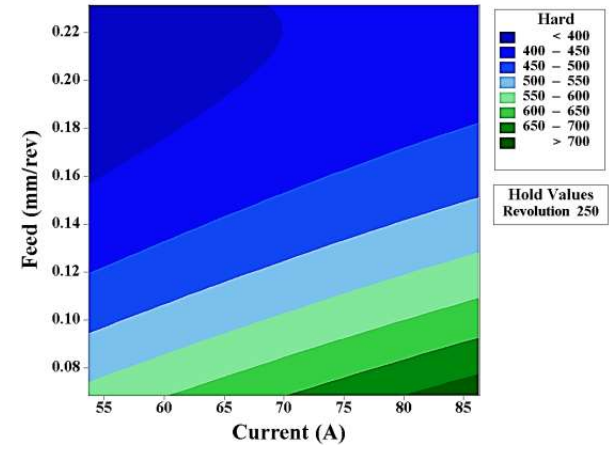

Figure 13. Contour diagram of feed rate and current value to surface hardness

According to the above contour diagrams, the lower the spindle speed and feed rate are and the higher the current is, the better is the hardening effect. The optimization parameter planning and design can refer to the contour diagrams, figure 15 shows the optimization parameter design, when the spindle speed is $168 \mathrm{rpm}$, the feed rate is $0.68 \mathrm{~mm} / \mathrm{rev}$ and the current is $86 \mathrm{~A}$, the hardening effect can be maximized.

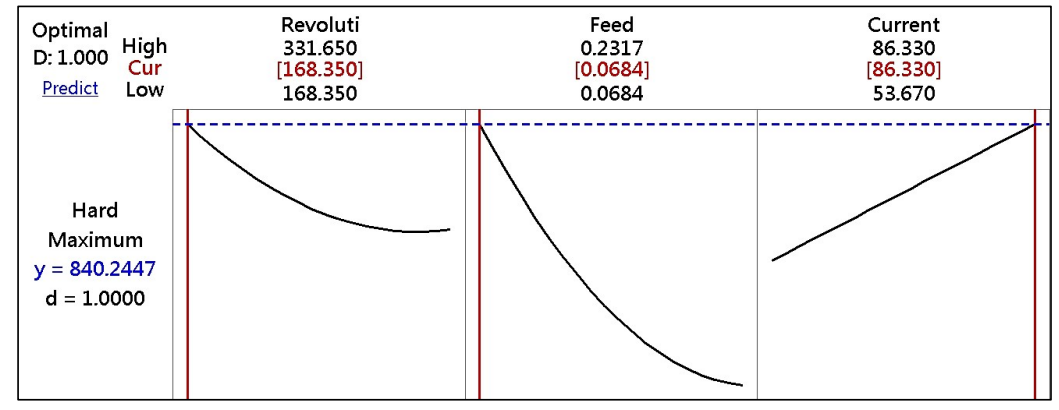

Figure 15. Optimum parameter design.

Finally, the RSM is used to establish the optimal mechanical hardness for the validation experiment, the experimental results are shown in Table 10, the hardening effect is 806 HLD (61 HRC), the error between the experimental result and the optimum solution from the model is $4 \%$, the material hardness value is increased by $163 \%$. The metallographic structure shows that the original flake graphite chemically reacts with peripheral ferrite due to the high temperature, the cementite is precipitated $\left(\mathrm{Fe}_{3} \mathrm{C}\right)$. figure 16 shows that many white dots are steatite, the material contains phosphor element, iron element, and carbon element, which form the $\mathrm{Fe}_{-} \mathrm{Fe}_{3}-\mathrm{Fe}_{3} \mathrm{p}$ ternary eutectic at high temperature, and then the steatite structure is precipitated, the substrate is supposed to be pearlite + 
austenite mixture, so the increase in the hardness may result from the cementite and steatite in the structure.

Table 10. Experimental results of optimum parameters.

\begin{tabular}{|c|c|c|}
\hline & Material hardness HLD & Optimal material hardness HLD \\
\hline Response value & 306 & 806 \\
\hline & \begin{tabular}{|l|l|l|l|} 
HLD & MI & T1 & tw \\
\end{tabular} & \begin{tabular}{l|l|l|l} 
HLO & M1 & $\mathrm{T} 1$ & $\leftarrow$ \\
\end{tabular} \\
\hline & 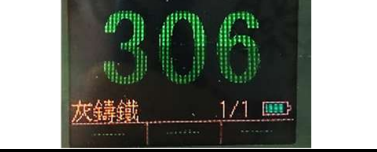 & 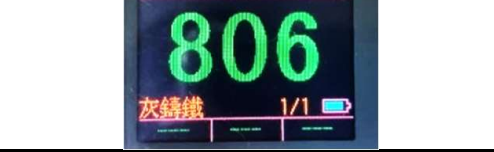 \\
\hline
\end{tabular}

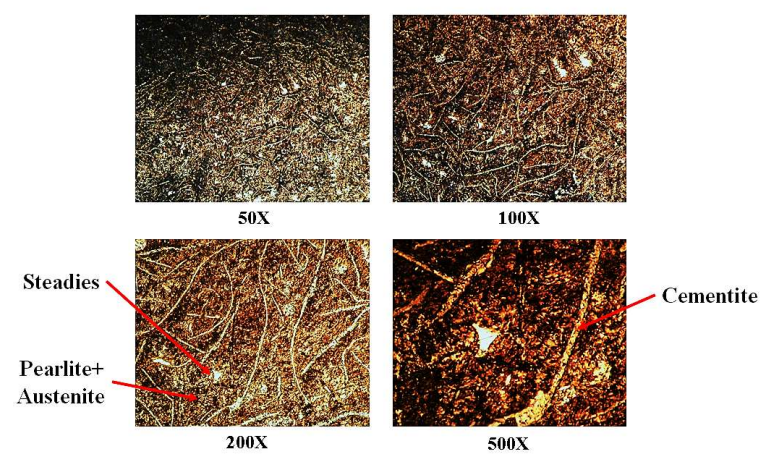

Figure 16. Material phase diagram of optimum parameters.

\section{Conclusion}

In the online heat treatment process, the method is used for process optimization and reducing the die cost. The experimental equipment includes a DC variable frequency plasma welder and CNC lathe for simulating the surface heat treatment process after mold machining, the actual effect of spindle speed, feed rate, and current factors on surface hardening are discussed. The RSM regression analysis model, ANOVA, Pareto chart, and Lack-of-Fit test statistics are used to discuss the interaction between significant factors and factors in the process. The design of the experiment is a full factorial experiment, the Central Composite Design is combined with RSM, to discuss the factor-surface hardness contour diagram and optimum parameters, validating the effect of optimum parameters on enhancing surface hardness. This study is concluded as follows.

1. According to the equation conversion and actual temperature rise measurement, the experimental machine thermal efficiency is 0.44 , the temperature prediction model is built according to 27 groups of experimental results of a full factorial experiment, the model equation is validated by $95 \%$ confidence interval, the actual temperature rises of five groups of validation experiment results fall in this interval.

2. The temperature model MPAE is $1.36 \%$, it is high accuracy prediction, the MAPE of temperature repeatability experiment is $1.41 \%$, it is high accuracy prediction.

3. According to the screening experiment result, the spindle speed is reduced by $100 \mathrm{rpm}$, the surface hardness is increased by at most $31 \%$, the feed rate is reduced by $0.1 \mathrm{~mm} / \mathrm{rev}$, the surface hardness is increased by at most $64 \%$, the current is increased by $20 \mathrm{~A}$, the surface hardness is increased by at most $34 \%$.

4. The metallographic structure of the material is pearlite + ferrite + flake graphite, when the surface hardness is 479 HLD, most of the pearlite in the structure is dissolved in the base pearlite. When the surface hardness is 613HLD, the flake graphite in the structure is changed into cementite structure, the 
cementite reacts with phosphor element to precipitate ternary eutectic steatite structure.

5. The optimization experiment uses 20 groups of Central Composite Design, the significant factor relationships are current $>$ feed rate $>$ spindle speed, the model and equation are validated by $95 \%$ confidence interval, the three groups of validation experiment results show that the average hardness values fall in this interval.

6. According to the contour diagrams and response surface diagram, the optimum parameters are spindle speed $163 \mathrm{rpm}$, feed rate $0.068 \mathrm{~mm} / \mathrm{rev}$, and current $86 \mathrm{~A}$. The material processing hardening objective of optimum parameters is 839 , according to the experimental results of optimum parameters, the experimental material is increased from 306 HLD to 806 HLD, the hardening effect is enhanced by $163 \%$, the error from the expected value is $4 \%$. In our simulated heating experiment, the simultaneous movement of the spindle and the saddle causes the difficulty of temperature measurement technology, so the high temperature and speed do not consider the measurement, however, not considered in the current and quenching study and maybe research topic in the future.

\section{Reference:}

1. Li M. R. Zhang J., Sun Y., 2003, "Application of Plasma Arc Quenching Process on Tank Parts", Journal of Shenyang University of Technology, Vol. 25, Issue 1.

2. Zhou Q., 2006, "Development and Research of Plasma Surface Quenching Control System", Shenyang University of Technology, Master's degree thesis.

3. Cui H. Z., Yin H. W., 2000, New technology of plasma beam surface hardening on a cylinder, Heat Treatment of Metals, Vol 3, 28-29.

4. Yang L. J., 2007, Th.e effect of specimen thickness on the hardness of plasma surface hardened ASSAB 760 steel specimens, Journal of Materials Processing Technology, Vol. 6, 113-119.

5. Etsion I., 2005, State of the art in laser surface texturing, Journal of Tribology Transactions of the ASME, Vol. 27, 248-253.

6. Huang S. F., 2012, Laser surface hardening treatment of medium carbon chromium-molybdenum steel AISI4140, Journal of china university of science and technology, Vol. 50.

7. Chen H. Q., 2003, Research on Laser Surface Hardening of Tool Steel", Institute of Materials Science and Engineering, National Dong Hwa University, Master's degree thesis.

8. Lusquinos F., Code J. C., Bonss S.,et al., 2007, Theoretical and experimental analysis of high power diode laser (HPDL) hardening of AISI 1045 steel, Applied Surface Science, 254(4), 948 954.

9. E. J. N. L. Silva, J. F. N. Giraldes, C. O. de Lima, V. T. L. Vieira, C. N. Elias, H. S., 2019, Influence of heat treatment on torsional resistance and surface roughness of nickel-titanium instruments, Vol. 52, Issue 11, https://doi.org/10.1111/iej.13164.

10. Lin Y. C., Chen H. M., Chen Y. C., 2013, Analysis of microstructure and wear performance of SiC clad layer on SKD61 die steel after gas tungsten arc welding, Materials, and Design, Vol.47, 828-835.

11. Tasy L. W., Lin Z. W., Shiue R. K., and Chen C., 2000, Hydrogen embrittlement susceptibility of laser-hardened 4140 steel", Materials Science and Engineering A, Vol. 290, 46-54.

12. Rong Y, Zuo X, Chen N., 2018, Clean water-air alternative timed quenching (ATQ) technology: principle and applications, Jinshu Rechuli/Heat Treat Met., 43(4), 1-9. 
13. Kyriakos Komvopoulos, 2011, Mechanical Testing of Engineering Materials, University of California-Berkeley, Cognella.

14. Marcio Abreu, Jill Sundberg, Jessica Elfsberg, Stefan Jonsson, 2020, Morphology and mechanisms of cavitation damage on lamellar gray iron surfaces, WEAR, Vol.456-457,15.

15. Park I. C., Lee H. K., Kim S. J., 2019, Microstructure and cavitation damage characteristics of surface-treated gray cast iron by plasma ion nitriding, Appl. Surf. Sci. 477, 147-153.

16. Dharmen TailorK. N. SrinivasanS. A. ChanniwalaM. Sohel M. Panwala, 2009, Simulation of temperature field of TIG welding using FDM, ASME, Pressure Vessels and Piping Conference.

17. Jung N. H., Ahn J. H., Lee M. J., Kang N. H., Cho K. M., 2019, Formation Behavior of $\delta$ Ferrite Within LB and GTA Weld Zones of Mod. 9Cr-1Mo Steel in Terms of Thermal History, Korean Journal of Metals and Materials, 56(2), 93102. DOI: https://doi.org/10.3365/KJMM.2018.56.2.93

18. W. Zhongyin, D. Liguang, and X. Faren, "Study of heat conduction mathematic model of plasma hot machining," Journal of Guangxi Institute of Technology, vol. 5, no. 4, pp. 45-50, 1994.

19. H.-Y. Bor, A Study on the Elevated Temperature Brittleness and Fracture Mechanism of Mar-M247 Super-Alloy, National Chiao Tung University, Hsinchu, Taiwan, 1998.

20. Chen S. H. and Tsai K. T., 2018, Predictive Analysis for the Thermal Diffusion of the Plasma-Assisted Machining of Superalloy Inconel-718 Based on Exponential Smoothing, Advances in Materials Science and Engineering Vol. 2018, Article ID 9532394

21. Jiang Y. S., 2018, Machinery Materials II, National Taiwan University of Science and Technology Books.

22. Liu G. X., 2014, Engineering Materials Science, Quanhua Books.

23. Milton Ohring, 1995, Engineering Materials Science 1st Edition, Academic Press

24. Dong J. L., 1985, "Steel Material", Sanmin Publishing House

25. Angela Dean, Daniel Voss, Danel Draguljić, 2017, Response Surface Methodology, Design and Analysis of Experiments, pp 565-614

26. Russell R. Barton, 2016, Response Surface Methodology, Encyclopedia of Operations Research and Management Science, https://doi.org/10.1007/978-1-4419-1153-7_1143.

27. LEWIS.C.D, 1982, Industrial and Business Forecasting Methods, London: Butterworth.

28. Aref Shokri, 2018, Application of Sono-photo-Fenton process for degradation of phenol derivatives in petrochemical wastewater using full factorial design of experiment, International Journal of Industrial Chemistry vol. 9, 295303. 